\title{
The new Manchester Road bridge in the Port of London
}

R. E. WEST

\section{Mr P. C. Mornement, Bertlin \& Partners}

I should like to comment on some problems associated with the Scherzer type of bridge with particular reference to experience I have had with a bascule bridge in Bombay which was commissioned in 1964 and has been working satisfactorily ever since.

66. The Author has referred to three difficulties with a Scherzer bridge: the high bearing pressure on the tracks, the heavy foundations needed and the difficulty in making the bridge run straight. The first two aspects are dependent upon the weight of the moving parts. This weight is independent of the type of bridge, but is a function of the span and the lever arm to the counterweight. The greater the lever arm the less force on the bearings or rolling track but the greater is the distance the bridge has to move.

67. Nowadays, tracks are much less of a problem than they used to be. Formerly, bascule bridges had built-up webs and a relatively thin track. The heavy rolling pressure used to give rise to working and fretting corrosion between the back of the track and the built-up web. This can be avoided with modern techniques. In the Bombay bridge the rolling surface was $230 \mathrm{~mm}$ wide. The curved track was a $520 \mathrm{~mm}$ deep casting tapered at the back to the same width as the web plate to which it was welded so that by the time the stresses reached the weld they had been dispersed over a considerable length. The straight track was a casting $460 \mathrm{~mm}$ deep, bolted to a girder spanning between the lock wall and a well sunk to rock behind the wall. This track was $450 \mathrm{~mm}$ deep, so that the stresses were reduced at the junction with the main girder.

68. One problem encountered in construction was in obtaining a uniform bearing between the straight track and the fabricated supporting girder. The track had a machined lower surface but the top flange of the girder could not be fabricated to the same degree of accuracy. Consequently, the track casting was tightened down on to a prepared bed of shims $1 \mathrm{~mm}$ thick, holes drilled at intervals through the track and the shims and an epoxy grout injected. This has worked very well and given no trouble.

69. It is true that a Scherzer type bridge requires a heavy foundation to take the rolling weight but bascule bridges are normally sited at lock entrances and the lock wall will provide a very good support for a girder to support the rolling weight. In Bombay, the track girder spanned between the lock wall and a well sunk to the rock behind the wall, A rocker bearing was provided over the well and a roller bearing at the back of the wall so horizontal forces were not imposed on the wall. During construction the need to insist on proper testing was illustrated. The roller bearings for the track girders were of high strength steel of small diameter. The specialist fabricator of the bearings said it was not necessary to test them as he had made many of them and there had never been any trouble. Nevertheless, we insisted on a full strength test on all the bearings and some failed. It was found that the specialist manufacturer had inadvertently made the bearings from the wrong type of steel.

70. As to running straight, all I can say is that the bridge in Bombay has been in operation for six years and no problems with this have been reported. Wear on the locating pins has been very small.

71. One problem with the Scherzer not mentioned by the Author is the question

Paper published: Proc. Instn Civ. Engrs, 1971, 48 (February) 161-194. 
of clearance. The normal type of Scherzer bridge is operated by a trolley in the elbow of the bridge, which is driven backwards and forwards on a gantry by a rack and pinion. When the bridge is in a vertical position there is a good clearance to the bridge, but not so much to the front of the gantry.

72. In Bombay, however, it was at first considered adequate and tenders were invited and a contract placed on this basis. The client then realized that some of the vessels he wished to bring through the lock needed greater clearance.

73. There were two basic solutions. One was to increase the span by some $4 \mathrm{~m}$ so the gantry was kept well back from the cope. This would have cost a great deal of money. The other, which was adopted, was to move the gantry back and insert a link between the operating trolley and the bridge. The additional cost of this was not large, even though the contract had already been let.

74. Besides increasing the clearance, the link permitted an elegant solution for dealing with the movement of the bridge under live load. The Author has dealt with this by arranging for the last section of the track to be sprung. In Bombay, small ramps were provided on the track so that the trolley lifted up by about $20 \mathrm{~mm}$ in the 'bridge down' position giving clearance between the pinion and the rack so that when a load came on the bridge, the trolley could move forward slightly without turning the machinery or straining the gantry. Sliding surfaces, which can be difficult to maintain, were thereby avoided.

75. I should like to ask one question. Does the Author think it advisable in all circumstances to make the bridge span torsionally stiff? I would have thought there would have been trouble in the event of an accident, in that a small impact at the side could distort the bridge, and be difficult to straighten: whereas if the span is torsionally weak it would be easier to repair.

\section{Mr J. A. Williams, Sandford, Fawcett, Wilton \& Bell}

My firm is at present acting jointly for the Department of the Environment and the British Transport Docks Board for the provision of a new opening-span bridge to take the A12 trunk road over the harbour entrance channel at Lowestoft. The span, which is $75 \mathrm{ft}$, is similar to that of Manchester Road, and it is consequently very interesting to me to compare the development of our project with the one described in the Paper.

77. From $\$ \$ 14-20$, it would appear that our respective initial studies followed similar lines. For instance, we also found a swing bridge to be attractive from first cost considerations, but in our case we ultimately recommended a double-leaf trunnion bascule as the most favourable solution for the particular conditions at Lowestoft, having regard to approach layout, land usage and aesthetics as well as cost. Incidentally, our bascule design is replacing an old swing bridge and during the interim period there is a temporary retractable bridge in operation, so we are experiencing a fair cross section of moving bridges.

78. I disagree with the Author's plea in $\S 21$ for standardization of design loadings, as these surely must depend upon individual circumstances. At Lowestoft where it could be important to admit a vessel to harbour in storm conditions, and equally vital to restore road traffic on a busy trunk road as quickly as possible, the bridge will be capable of operating between stops in $45 \mathrm{~s}$, against a wind loading of $19 \mathrm{lb} / \mathrm{sq} . \mathrm{ft}$ derived from $70 \mathrm{mile} / \mathrm{h}$ winds. In fact, this wind loading largely influenced the selection of a double leaf design. It also very early on ruled out the otherwise possible advantage of an aluminium superstructure as was adopted for the Hendon Dock bascule erected at Sunderland soon after the war.

79. Referring to $\S \S 24$ and 25 , which state, respectively, that $30 \mathrm{lb} / \mathrm{sq}$. $\mathrm{ft}$ and $10 \mathrm{lb} / \mathrm{sq}$. ft were adopted at Manchester Road, am I correct in thinking that this means the bridge will operate normally at $10 \mathrm{lb}$, but at over $10 \mathrm{lb}$ it will be held stationary by the brakes, with the whole system safe up to $30 \mathrm{lb}$ ? 
80. Why were these towers designed in steel plate? Weight does not appear to be critical, and I suggest that construction in reinforced concrete would have given stiffer structures with reduced deflexion problems, would have reduced maintenance costs, and could have been expected to be cheaper in first cost.

81. With regard to the counterweight, referring to Fig. 14 'cast steel' should presumably be 'cast iron'. At Lowestoft we designed our counterweights as cast iron, but after the award of a contract, the Contractor offered a redesign using concrete with a significant reduction in price.

82. For a scheme involving civil, electrical and mechanical work, with closely interlocking setting-out and co-ordination problems, we decided that it was essential to have the whole project included in one comprehensive contract, with one contractor bearing ultimate responsibility. The Author decided otherwise. Was this wholly due to the existence of the Port of London Authority's maintenance contract ? Had that not been a factor would the Author have opted for a single contract?

\section{Mr T. M. Craig. MacTaggart, Scott \& Co.}

Much interest was evident as a result of the Author's Paper in the hydraulic operating machinery for the bridge and it might be appropriate to offer some general remarks concerning the installation. A hydrostatic transmission system is used which consists of a hydraulic motor connected in a closed loop to a hydraulic pump. The pump is driven by a constant speed electric motor and its output is controlled to give an infinitely variable rate of flow; the rate of flow determines the speed of the hydraulic motor and hence the speed of the bridge movement. The fluid pressure generated by the pump is merely a reflexion of the load which the motor has to overcome. The fluid output of the pump is controlled by varying the stroke of the pistons, from zero to maximum stroke; the adjustment of this stroke is by cams which are driven through gearing from the bridge trunnion. As stated by the Author, the profile of the cams is calculated to give the required acceleration and deceleration characteristics. When the bridge is moving at full speed the pump is on maximum stroke, and therefore the cams are only placed at the extremities of the bridge travel to achieve acceleration or deceleration. The advantage of using cams is that once the correct profile has been obtained consistent performance can be guaranteed and the necessity of using buffers to cushion the final movement of the bridge is obviated.

84. The new Manchester Road bridge has two pumping sets and eight high-torque low-speed hydraulic motors, four to each rack. Each pumping set has, as stated, a main variable output pump plus a small auxiliary pump: the latter pump supplies fluid for operating the auxiliaries such as nose bolts, hand rail collapsing, brakes, and also assists in the control of the main pump stroking gear. Under normal operation both pumping sets supply fluid to all eight motors: if, however, one pumping set is out of commission the other can operate the bridge in complete safety, against maximum designed loading, but at half normal speed. Similarly any of the hydraulic motors could be removed: in this case the operating pressure would rise to obtain the necessary output from the remaining motors. Since the pumps would be delivering their normal output, the speed of the motors would increase. The system is safeguarded from running with excessive pressure by two units: firstly a normal pressure relief valve and secondly a 'buckling control'. The buckling control reduces the pump stroke progressively with increasing pressure (once a predetermined level has been reached) thereby preventing overload of the electric motors.

85. The system is designed with all functions 'failing-to-safe': should there be hydraulic pressure failure or electric failure, the brakes, which are multi-disc spring applied hydraulically released units, automatically engage. Their torque capacity is approximately three times that of the maximum motor torque. Extensive duplication of units has been designed into the circuit such that should a breakdown occur with a unit, it can be by-passed with the bridge still operative. If there is an electricity failure a standby alternator can drive the pumping sets through lower powered 
electric motors which are mounted on top of the main motors and which chain drive the main shaft. Speed is naturally reduced (by using the buckiing control) but full pressure can still be generated by the pumps.

86. The advantages of using a hydraulic transmission are compactness, the ability to mount the drive units remotely from the pumping sets, ease of control and reliability. Additionally the maintenance is extremely low and the fluid cools and lubricates the hydraulic machinery and the system is not adversely affected by weather. Properly installed and after initial adjustment the equipment should provide extremely long and maintenance free service. Of great importance is the necessity of using clean oil and of making certain that all the units are completely free from dirt before commissioning. A closed circuit is used and there are no easy paths for the ingress of dirt other than when the equipment is opened up and this is when particular attention must be paid to cleanliness. This should however be a rare requirement, and is not called for during regular maintenance.

87. Installation of pipework used to involve brazed joints and flanges which were sources of potential dirt: presently very efficient ' $O$ ' ring type couplings are used which make for easy and clean installation work.

\section{Mr G. B. Lewis, Heap \& Digby. Ltd}

The amount of information on the operating mechanism is a little scanty, and it would be helpful at a later date to discuss in more detail the equipment that causes the bridge structure to move and, more particularly, the small control components that make sure the machinery does its job in the correct order, and does not injure itself in doing so.

89. Referring to $\S 24$, it is accepted that the wind loading of such a bridge is the principal factor governing the rating, and hence the cost, of the operating machinery. The forces required to operate the bridge in normal circumstances are balanced by the counterweight and are comparatively small. It is only when the surface of the bridge has to move against the wind that the capacity of the machinery is used to its full extent.

90. The rating of the operating gear is also governed by the time in which the bridge is required to carry out its movement, though the Author has reminded us that this time, which starts at the moment the locks are withdrawn with the bridge in one position until they are inserted again in the other position, is small compared with the overall time which elapses between the moment when road traffic is signalled to halt, and that when waterborne traffic is signalled to proceed.

91. It seems that the classical design parameters for the rating of bridge machinery are, first, the operating time; secondly, what I term the Design Wind Load, which represents the highest speed at which the bridge must be able to complete its movement in the prescribed time. It may be noted that in still air I would not expect the bridge to undershoot the operating time. The third parameter is the maximum operational wind speed which is represented by the Operational Limit Wind Load. That is the wind speed at which I would expect the bridge to stall (but not to damage itself thereby) and having stopped to be held by the brakes until, with falling wind, the operator restarts the mechanism. I allow that at wind speeds between the Design Wind Load and the Operational Limit Wind Load an extended operating time would be permissible. There is of course a limit on period by which the operating time may be extended.

92. It seems to me that selection of the Design Wind Load is not a matter for a code of practice, but one in which the engineer must use his experience and expertise. The factors he has to take into account in arriving at that are the types of vessels which may use the waterway, and the ability of crews to handle them under adverse weather conditions. In connexion with the Lowestoft bridge to which Mr Williams referred (it was then a swing bridge) I recall at the beginning of the war seeing trawler 
skippers take their craft through that channel under gale force wind conditions when passage appeared to be impracticable.

93. Secondly, the extent to which the site is exposed or sheltered would be a guide to the operational limit wind speed one could work to. Thirdly, the relative priorities of the waterway and the roadway should be considered. At the Manchester Road bridge it is, I think, the roadway which has priority, whereas at Lowestoft it is undoubtedly the waterway.

94. I endorse and understand the advantages of the low-speed high-torque pressure oil motor (\$ 45): I am never certain about the use of the term 'hydraulic' in this context. I should like the Author to give some information about the overall working characteristics of the hydraulic motors and of the pumps to which they are connected.

95. In $\S 46$ the Author states that the common solution is to provide inching motors to deal with the final landing of a heavy mass. I hope I may prevail upon him to qualify, and possibly even withdraw, the reference to what I look upon as not at all a desirable way of achieving the solution of the problem of reducing speed to zero. I would like to know that people who read the Paper in years to come are left in no doubt that we are aware we can achieve a controlled rate of change of speed from full to halt, possibly with regenerative braking.

96. I am most impressed with the ruggedness and simplicity of the cam control system. It must be borne in mind, however, that this can, of necessity, only operate at the extremities of the run of the bridge. Whenever the bridge is halted, either due to electricity supply failure or because it is not required to be fully raised, we must rely for deceleration on the characteristics of the brake; I would like to know the extent to which that characteristic can be controlled. Acceleration from an intermediate position halt is governed I assume by the characteristic of the electric motor, the pump and hydraulic motor.

97. I should like the Author to comment upon the extent of any difficulty he may have had during installation and commissioning with dirt or debris in the hydraulic pipework. It seems that is a point which will have to be watched in these installations with very great care to make sure that the pipework and internals of the motors and pumps are not subjected to abrasion or erosion.

\section{Mr J. H. Gabony, Port of London Authority}

You may have wondered why the Authority built this bridge in one of the Upper Docks where many facilities have been closed down over the past few years. Despite the closures at London and Surrey, new berths have been built at the India \& Millwall Dock, and it is anticipated that these new facilities will have a reasonable life.

99. In addition, you will see from the Paper that the old bridge was in need of extensive repair. The decision between repair or replacement was finely balanced, but the damage resulting from two ship collisions, finally helped to make up our minds in favour of replacement.

100. The other thing that has to be taken into account, is the policy of rationalization of entrances at all the enclosed docks. Entrances and bridges are expensive to maintain, and in our present economic situation it is necessary to reduce operating costs. We found that many entrances were expensive luxuries, and the India \& Millwall Dock system, and Tilbury Docks, now operate on only one entrance. So, in this setting, the provision of a new bridge also made sense if we want the most efficient results from the one entrance at India Dock.

101. Then, there are the obligations to the residents of the Isle of Dogs. They consider themselves a community cut off, because of inadequate bus services, lack of schools, etc., and as you know, they attempted to set up their own State and declared UDI in 1970! I think that the speed of operation of this bridge must have a psychological effect on the inhabitants travelling to and from the 'island' and, indeed, the brilliant colouring must have an amenity value in this rather drab area. 
102. There is an interesting spin-off with this new bridge because of its ability to take heavy loads. For a fairly small expenditure along the road leading from the bridge to Poplar, we can eradicate many of the problems we have had in getting heavy lifts into these Docks.

103. I would correct one of the previous speakers, who thought that we gave priority to shipping. This is not strictly true, because wherever we have road bridges used by the public, we do try to take into account the needs of other industries. There are certain times in the day, e.g. before or after normal working hours, and during the lunch time, when bridges are normally kept open for pedestrian and road traffic. They are only swung during these periods if it is absolutely necessary from a navigational point of view.

\section{Mr M. Rundle, Consulting Engineer}

The Author quite correctly diagnoses the causes of deterioration in the structure of the rolling lift bridge, which was built in 1929, but when he goes on to say that the very high pressures at the point of contact between the curved and horizontal paths sooner or later result in local crushing, I think he overstates the position a little. There are very many Scherzer bridges in service of later design where the serious effects of high loads had been considered, and wider tracks mounted on heavier segment girders and stronger foundation girders provided.

105. With many of these bridges, the most serious trouble arises from the coldrolling effect on the track castings and of course wear results in incorrect meshing of the rack and pinions. Even with the old Manchester Road bridge where the structural weaknesses became apparent as long ago as 1951, there was little sign of further deterioration over the next 18 years. The situation had of course to be kept under close scrutiny and the question of effecting major repairs was frequently considered. Because the location of the bridge was so important to both road and water borne traffic a detailed study was made in 1965 of the task of repairing the bridge so that it would be satisfactory for another twenty years. In these studies both the cost and time to undertake the repair were thoroughly analysed. In order to ascertain the minimum length of time the bridge would be out of service with consequent disruption of the road traffic, use was made of critical path analysis and resource allocation methods. It was found that rapid repair could be programmed at a price which was considerably lower than the cost of a new bridge. Unfortunately serious damage to the bridge referred to in the Paper meant that the financial saving over the cost of a new bridge almost disappeared.

106. With reference to the operating machinery used on the new bridge, the use of hydraulic motors giving high torque at very low speeds was seen to possess great advantages over the more conventional electric motor driven system with its attendant gearing, limit switches and multiple machine arrangement. The cam control of the variable output of the pumps is simple and gives accurate speed over the whole moving cycle. The Author has referred briefly to the hydraulic control circuits and made passing reference to the braking system employed, and the design of the brakes. With a moving structure having a total weight in excess of 500 tons, braking without introducing excessive structural stresses, particularly under emergency conditions or in high winds is a very important matter, and I would hope that the Author might explain what design considerations arose when analysing braking effects, and describe more fully the principle of operation of the braking system.

\section{Mr R. Huggins, Docks Engineer, India \& Millwall Docks}

The Author has drawn attention to the high factor of economy in his bridge which was derived from the fact that the new bridge was placed upon the foundations of the old. It has had obvious benefits in cost savings when you remember the very high cost of the foundations of such heavy structures as we have under consideration. 
Consequently, it was necessary, as a pre-design matter, to investigate the strength of the concrete in the existing foundations, and accordingly the cementation company undertook borehole drillings to extract cores from the existing foundation concrete. In fact the first bore attempted to extract a core 4.6 in. in diameter, but the going was very hard, and unfortunately it was not possible to pursue this core. Eventually we had a core of 3.78 in. external diameter, and the boreholes were taken to considerable depth. The biggest core was taken from about $18 \mathrm{ft}$. The two boreholes were situated on each of the tower foundations. The cores derived from the boreholes varied in dimensions from pieces as small as 6 in. dia., and in borehole No. 2 those dimensions were 6 in. and 7 in. and 7 in. In borehole No. 3, which was the riverside tower foundation, $12 \mathrm{in}$. cores were extracted. The concrete varied in density between $138 \mathrm{lb} / \mathrm{cu}$. $\mathrm{ft}$ and $146 \mathrm{lb} / \mathrm{cu}$. $\mathrm{ft}$ which, I think you will agree, is not at all bad.

108. This gave under test core strengths of between $2420 \mathrm{lb} / \mathrm{sq}$. in. up to $4400 \mathrm{lb} /$ sq. in. and the equivalent $6 \mathrm{in}$. concrete cube strength derived from those figures was $3220 \mathrm{lb} / \mathrm{sq}$. in. and $5900 \mathrm{lb} / \mathrm{sq}$. in. So I am sure the Author will confirm that he was able to rely on very fair concrete strengths in the existing foundations, and in fact he has said that structurally speaking, the towers could have been smaller in crosssectional area. In fact, for reasons of access and physical housing of the gear, they were oversize. I think it worth mentioning that the approximate cost of the investigation was about $£ 3000$ of which the major factor was the use and waste of diamond bits which came to about $£ 1800$.

109. I should like to refer to a point made by a previous speaker in connexion with the hydraulic piping. This type of control and operation was used in the Glengall Grove footbridge to which the Author made reference in his Paper, and this bridge was extensively piped. The method used to prevent dirt and foreign matter entering the system was a pickling at the works to remove mill scale. There was further pickling on site and the sealing off of each length of pipe prior to being incorporated in the installation. In fact experience has shown that there has been no cause for concern in the operation of the Glengall Grove bridge on this account since 1965.

110. Mr Mornement mentioned that he thought the bridge might be vulnerable to a blow from a vessel. A week ago the bridge received a minor blow and suffered no ill effects from the point of view of operation, although the riverside vertical link received a set of something like 2 inches.

\section{Mr D. Pope, Bertlin \& Partners}

I should like to ask the Author two questions on the choice of location of the bridge.

112. It is stated in the Paper that the bridge was located in the south side of the entrance because prevailing wind and tide conditions suggested that an impact would be more likely to occur on the north side, and the bridge when fully opened does not provide as much clearance as would have been desired. In fact this appears to be a case where theory and practice are in conflict, because both the accidents which were reported occurred on the southern half of the bridge. I understand that the new bridge has been hit, and I should like to ask whether this impact occurred on the southern or northern half of the entrance.

113. The other question relates to the choice of the alignment. Here the conflict is between the conditions when the bridge was in position and operating, and the conditions which prevailed during construction. The Author mentioned that if the new bridge had been aligned alongside the existing structure, it would have been possible to keep the old bridge in operation until the new bridge was complete. I would have thought that the residents in the Isle of Dogs would have preferred this arrangement, despite the fact that once it was in position in this slightly different alignment, $6 \%$ of road user time would have been lost while vessels were occupying the lock. It is interesting to note that the two previous bridges on this site were in 
position 36 and 30 years respectively, and if it is assumed that the present bridge will have a similar life, then $6 \%$ of this period is about 2 years.

114. It is not stated how long the road was closed for, but I imagine it was between 12 and 18 months, and it is possible that a total period of 2 years spread over the life of the bridge during which the road was closed, would have been preferable to completely severing this vital access to the Isle of Dogs for a period of 18 months. Were the local residents consulted on this point?

115. Reference has been made to the fact that the tower has a bigger base than it needs from structural considerations. The bridge, generally speaking, is a very elegant structure, but the towers are not as elegant as they might have been. Was any thought given to the idea of tapering them towards the base, because the critical dimensions are required at the top where the rack and pinion mechanism is housed, and a tapered shape might have blended well with the elegant tapered shape of the top boom?

\section{Mr G. A. Wilson, formerly Director of Engineering. Port of London}

This was about the fourth or fifth moving bridge that I renewed in the docks in London, and by that time there were certain things I knew I did not like about moving bridges, and was hopeful on this occasion that if we had a new bridge it would be one with which we could be satisfied. I knew I did not like Scherzer bridges. Mr Mornement made quite a good case for his Scherzer bridge. Mr Rundle also said they were not bad, but I remember when I first went to London, Adrian Porter of the Mersey Docks and Harbour Board said, 'Have you any Scherzer bridges? You will have trouble with them in 25 to 30 years', and he was right. Troubles came along, and they almost always started with the foundations on which the bridge rolled. But I have to support Mr Rundle's statement that improvements were made. We studied all our bridges and proved in theory that the latest bridge at Tilbury was a much better design, and it gave no trouble. But still we were in that 25 or 30 year range, and there may be trouble in time. However, as the plan of Tilbury has changed so radically, a replacement may not be required.

117. Coming to the Manchester Road bridge, after various repairs it was obvious that the foundations, the tracks and the quadrants would have to be rebuilt. The machinery was in poor state, and even when overhauled there would still be two sets to look after. So much expenditure on an old bridge could not be justified.

118. Then considering the new bridge, I asked the Author to examine bridges in North European ports to see if he could achieve an elegant and reliable design with straightforward maintenance. Another important change which can be incorporated in new design is automatic operation which saves skilled labour. It is only recently that men have started to show willingness to operate such changes.

119. The bridge has now operated for sufficient time to test the design and permit me to say it is an innovation which could be used successfully in other places.

\section{Mr A. C. D. Malcolm, Crown Agents}

A previous speaker mentioned the testing of the roller bearings, and $I$ see in the Paper that particular attention was paid to inspection of the fabrication. Could the Author tell us whether the Port of London Authority delegated this inspection to an independent authority or whether their own inspection staff carried this function out? Could he also indicate the other points where it was felt necessary to have supervision by inspection?

121. Another speaker said you pay your money and you get what you pay for. Having been an Inspecting Engineer for a quarter of a century I doubt that. You pay your money certainly, but you do not necessarily always get what you pay for, unless somebody takes the trouble to check at all stages.

122. Last, I would, with hindsight, mention that I do know that hydraulic 
piping gives trouble. We have had it in hydraulic gearboxes manufactured by a very famous German firm, and they have gone into rather famous locomotives on a less famous railway, and have operated satisfactorily up to a point. But dirt somehow does appear and causes trouble. Only the most stringent inspection of the assembly during all stages of manufacture and at the stage of putting into service can overcome this problem. No amount of cleaning dirt out or blowing through cures the problem.

\section{Mr G. M. Beresford Hartwell, Consulting Engineer}

I feel that although there has been a good deal of defence this evening of the Scherzer bridge, it requires a little more. I had the task a week ago of examining a Scherzer bridge with fixed machinery. The drawings of it are dated 1912, and I have to say that this bridge, apart from some alterations to its machinery, seems to have been operating perfectly since that date. There was some wear which necessitated some modification, and in fact the operators wish to increase the speed of operation of the whole bridge. However, there is a bridge of considerable age which is still quite intact and working very reliably. It is in fact the only bridge across the harbour, operates about three or four times a day, and has not given rise to any complaint.

124. I would ask the Author if he could tell us to what extent the methods of operation of Manchester Road were open to choice at the beginning of the exercise, and to what extent they were dictated by the overall bridge design. With the modern tendency towards improved oil hydraulic systems there seems to be uncertainty as to the relative advantages of racks driven by hydraulic motors and the use of long cylinder type actuators. It would be interesting to see whether this method was considered in the early stages of Manchester Road, or whether it should be considered in a comparable situation now.

Mr R. Bird, Mactaggart Scott \& Co.

A quick résumé of the hydraulic circuit may be helpful to clarify the general operation of the bridge.

126. The basic hydraulic circuit is a simple closed-loop circuit where you have a hydraulic pump driven by an electric motor, which supplies fluid to low-speed hightorque hydraulic motors. Pressure fluid comes from the pump at $2500 \mathrm{lb} / \mathrm{sq}$. in. direct to the motors and returns at reduced pressure into the suction side of the pumps. Fluid has to be added to the circuit to make up the leakages, and it is done by a small supercharge pump. The circuit looks complicated, but most of the other equipment is for sequencing the auxiliary components. The basic circuit is indeed a very simple circuit.

127. The pump is a variable speed pump, the further you put it on stroke, the more fluid is delivered and the faster the motors rotate. The stroking of the pump is done by a cam mechanism driven directly from the bridge. The cam only operates the final stages of the bridge prior to opening or closing. The cam operating mechanism on the bridge has been geared up in order to have longer activating travel than would be the case if the cam was driven directly off the trunnion.

128. The brakes, which are housed within the hydraulic motor casing, are fail safe disc brakes, the moving discs being attached to the motor drive shaft.

129. On the question of cleanliness in hydraulic circuits, the circuit must be clean and this is ensured by the use of filters. We have this equipment operating in all types of conditions, and as long as the pipes are properly pickled, we have no great trouble with dirt. This basic equipment has been used successfully in the Glengall Grove footbridge and on the bridge under discussion, and it is proposed to use the same basic equipment on the Lowestoft bridge. 
Mr E. M. T. Powell, Mott, Hay \& Anderson

Referring to the various types of moving bridge considered in the Paper, whilst for the case in question the trunnion bascule type would have required low level pits, this type of bridge does have clean lines without protrusions above the bridge deck and a pleasing appearance overall without the disadvantages and complications of the swing and retractable types. For longer low level bridges a compact arrangement of counterweights and machinery accommodated in slim piers can be obtained by careful design.

131. In considering the loading basis to be adopted for machinery design no mention has been made of driving motor starter/unsticking torques. Whilst the wind pressure against which the bridge operates does have an important bearing on the

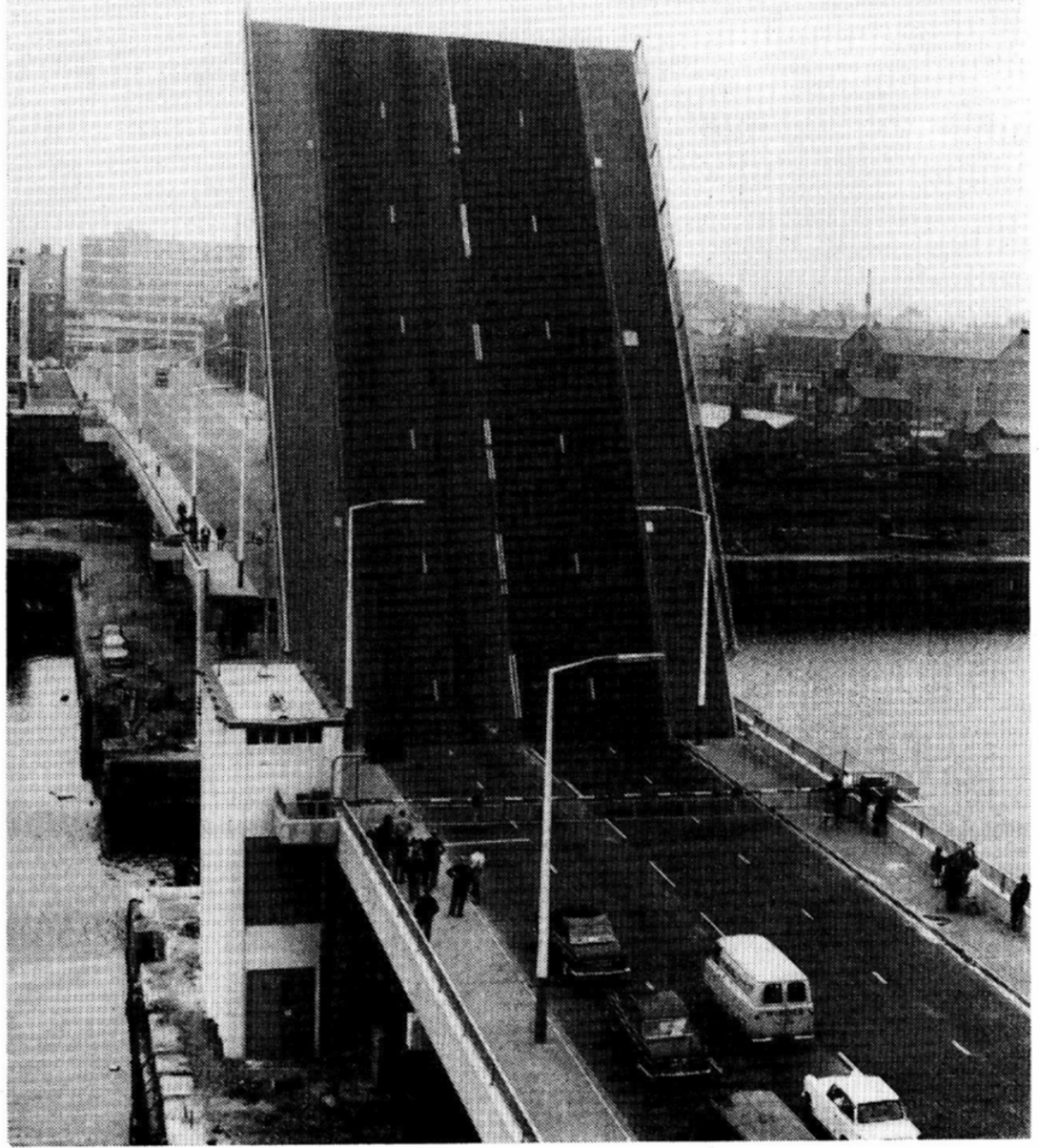

Fig. 30. The Michaelson Bridge 


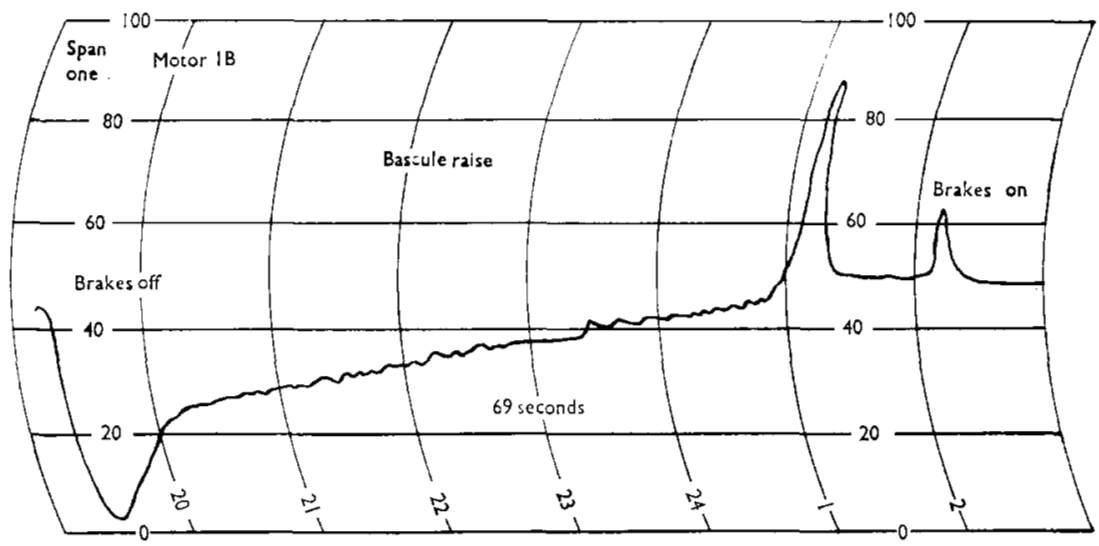

Fig. 31

machinery rating and may outweigh other effects when the bridge is in motion, the instantaneous load to be overcome at starting is a critical factor. Load/time characteristics have been taken at the Michaelson Bridge completed at Barrow-inFurness in 1968. The bridge is of the twin leaf bascule type with opening spans mounted side by side, each leaf being about $120 \mathrm{ft}$ in length from trunnion bearing to nose, $30 \mathrm{ft}$ wide and of weight 800 tons (Figs 30 and 31 ).

132. The characteristics, recorded with an instrument having a high rate of response, show the starting load, roughly equivalent to the machinery normal full load rating in this instance, lasting only for a very small proportion of the total opening time and thereafter falling away rapidly. It is therefore important to take advantage of any short time overload characteristics which may be inherent in the performance of the driving machinery and to select the machinery accordingly.

133. With regard to the proposal to standardize wind loadings, in view of the wide variation in the locations and degrees of exposure of sites, wind shading, gusting, etc., and also since shipping movements are often restricted in very high winds, any common standard would be of limited benefit and might well lead to oversizing and unnecessary expenditure. Publication of measurements taken on various bridges would of course be of great value.

134. Whilst the multi-motor drive direct on to racks described in the Paper is simple, it does suffer from the disadvantage that there is no ready means of disconnexion should any one of the eight motors seize or require attention during a period when bridge movement is necessary. A remotely initiated automatic clutch is often provided to overcome this difficulty and in this respect a single shaft drive through a gearbox is advantageous and enables much higher torques to be transmitted.

135. The use of a cam as a drive position reference is also a simple direct method, but as mentioned by previous contributors, difficulties arise if only partial openings are required. Various electrical or electronic shaft encoder systems are available which enable selected partial openings to be carried out automatically.

136. The number of bridges opening fully as normal procedure is probably limited and figures for Tower Bridge in 1950/51 (the machinery in which is now being renewed after 75 years' operation) may be of interest (Table 2).

137. Previous contributors have emphasized the advantages of the latest hydraulic drive systems, but recent advances in solid state thyristor systems coupled with significant reductions in cost may well re-establish the electrical direct current motor 
Table 2. Number of lifts for Tower Bridge, London

\begin{tabular}{|c|c|c|c|c|c|c|c|c|c|c|c|}
\hline $\begin{array}{l}\text { Percentage } \\
\text { of full } \\
\text { opening }\end{array}$ & $\begin{array}{l}\frac{1}{8} \text { and } \\
\text { under }\end{array}$ & $\frac{1}{4}$ & $\frac{1}{3}$ & $\frac{3}{8}$ & $\frac{1}{2}$ & $\frac{5}{8}$ & $\frac{2}{3}$ & $\frac{3}{4}$ & $\frac{7}{8}$ & Full & $\begin{array}{l}\text { Total } \\
\text { No. of } \\
\text { lifts }\end{array}$ \\
\hline Totals & 348 & 445 & - & 478 & 1215 & 432 & 407 & 83 & 9 & 95 & 3512 \\
\hline
\end{tabular}

as the best choice in terms of high starting torque, overload characteristics, reversing, regenerative braking, automatic control of acceleration, deceleration and reliability after long periods standing idle, coupled with compactness and low cost.

Mr W. Sefton, Consulting Engineer, Toronto, Canada

I found during my design of the Cherry Street bascule bridge in Toronto (Fig. 32), that there was very little information readily available on this subject. Sometimes, a scarcity of literature is a blessing in disguise because then it forces engineers to reapproach the whole subject almost from first principles and the result is often new concepts and new solutions. I prepared for the University of Toronto a thesis in September 1970 and in that thesis I included a bibliography. ${ }^{1}$

139. Since Waddell ${ }^{2}$ and Hovey $^{3}$ published their books before 1930, the only

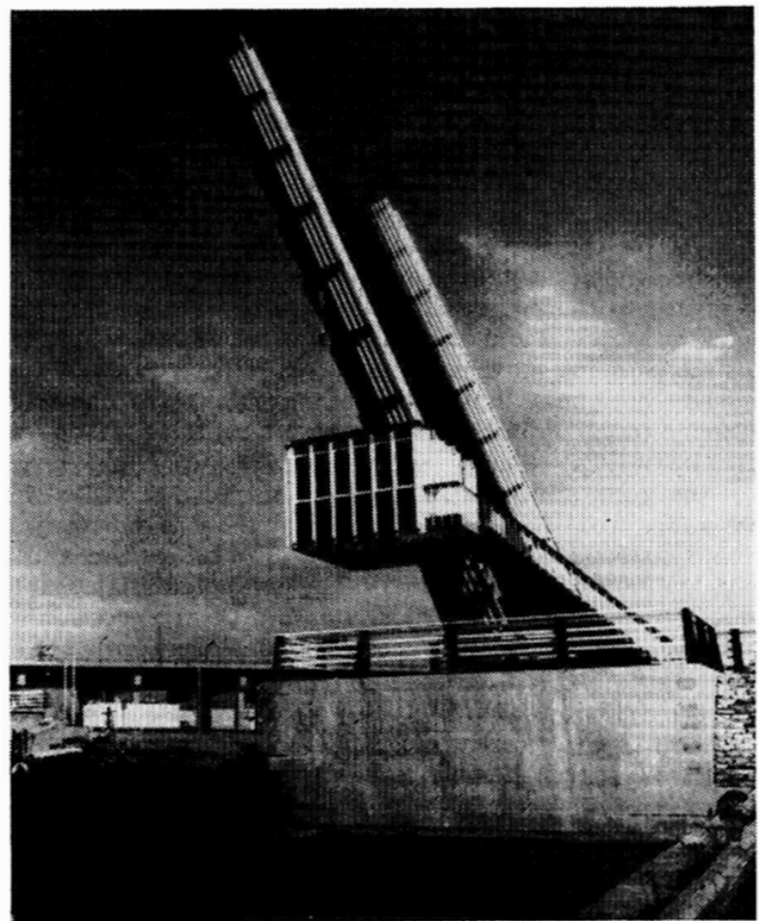

Fig. 32. The Cherry Street bascule bridge 
valuable book is the one edited by Hool and Kinne ${ }^{4}$ and reissued in 1943 with a new editor. The result has been that bridges built recently have tended to resemble bridges built in the early part of the century and earlier.

140. I am most impressed with the new Manchester Road bridge in terms of appearance and the designers appear to have given modern lines to a development of a classical system, although it is my own belief that there is no need for bridges to be obvious. However, if I believed otherwise, I would hope to have designed a bridge that looks as good as the subject of Mr West's Paper.

141. Waddell shows an illustration of Chicago's unsuccessful jacknife bridges which also had a roadway suspended by tension members. In those bridges the bridge leaf folded up rather like the military scissors bridges during launching.

142. I was interested to see also in the Paper an illustration of the Glengall Grove footbridge where the quadrant rack is fixed in space and the pinion is attached to the bridge leaf. Perhaps Mr West could tell me whether the idea of the fixed rack and the pinion attached to the leaf has been used for any other movable bridges carrying highway traffic. I used it in the Cherry Street bridge which carries four lanes of H25. S20 loading and in three years of operation there has been absolutely no indication of wear or maintenance other than routine regular greasing etc. by the bridge operator. This principle combined with a hollow room-sized counterweight gives greater freedom in locating the rack or racks without any reference to the location of the main girders. This is a substantial departure from the normal Chicago-type bascules built so far.

\section{Mr West}

The new bridge at Manchester Road replaced one of Scherzer type and several contributors to the discussion have commented on the considerations which led to an alternative type being preferred. It can, of course, reasonably be asserted that a modern bridge of any pattern would be an improvement on those built 30 or more years ago and Mr Mornement has described how several of the inherent defects were designed out for the Scherzer bridge in Bombay. Nevertheless, certain fundamental adverse characteristics are inescapable and they are not necessarily shared by other types.

144. Mr Mornement also posed the interesting question that if a torsionally stiff span were to be permanently distorted by an accidental impact could it not be very difficult to straighten it out again? Although this could happen, I rather think that any blow sufficiently severe to distort a stiff structure would be likely to cause even more extensive damage in one liable to twist. The torsionally rigid span at Manchester Road materially assists the structure in supporting uneven lane loading and also operation of the bridge by one rack only. It did, however, require accurate shop fabrication of sections to avoid subsequent difficulty in lining up before site welding.

145. Several contributors commented on the wind pressures for which moving bridges should be designed. As I mentioned in $\$ 24$ there has been no experience in the Port of London of a lifting bridge being prevented from opening because of high winds. It is not unreasonable to conclude from this that the pressures adopted for design in the past have been too high and I believe that some modern bridges also tend to be over-designed in this respect. Winds close to the ground may be expected to gust and one of the principal advantages of the hydraulic machinery at Manchester Road is that if the loading exceeds the design figure of $10 \mathrm{lb} / \mathrm{sq}$. $\mathrm{ft}$ for a short duration, the relief valves will simply blow and the bridge will slow down. If the machinery is allowed to continue operating, when the wind drops, travel will be resumed at the former speed. There is no possibility that any part will be overloaded. If the wind should be so severe that the bridge actually stops, or even tends to reverse, at what Mr Lewis defines as the Operational Limit Wind Load, then the brakes would be applied to hold the bridge stationary up to the storm loading of $30 \mathrm{lb} / \mathrm{sq}$. $\mathrm{ft}$. In addition, at Manchester Road the buckling valve in the system brings about a single step speed change at a wind pressure of half the Design Wind Load. 
146. Mr Williams is correct that the reference in Fig. 14 should have been to cast iron counterweight blocks. They are correctly described in $\S 34$ and, as they were surplus to requirements from the dock extension at Tilbury, were readily available.

147. The towers were designed in steel principally to reduce the site occupation period by enabling them to be fully fabricated before erection. They would also have been even wider in reinforced concrete and some very accurate site setting out of heavy bases and machinery supports would have been necessary.

148. A wide range of skills is required for moving bridges and it is difficult to decide upon the most suitable contractual arrangements. While management of a multi-disciplined contract can be simplified by having one main contractor, the fact must be faced that few firms will have available the resources to directly undertake civil, structural, mechanical and electrical work and they usually sub-contract those parts which they prefer not to do themselves. In the case of Manchester Road bridge, the PLA were able to provide the technical supervision necessary, from their own staff, to co-ordinate the various aspects of the work and it was therefore simpler and, incidentally cheaper, to have separate contracts. This arrangement was not particularly influenced by the decision to carry out the civil and electrical works under the maintenance contract. This was considered better suited to the small scale and flexible operations required within the confines of the docks and, in the event, no difficulties were experienced.

149. Mr Pope comments on the decision to close the road for the erection period, which was 10 months, rather than maintaining the old bridge in service while the new was constructed at the alternative position available across the lock. I have no doubt that the chosen arrangement was better and that road users were in the long term far less disrupted by a temporary closure than they would have been by having to wait for extended periods indefinitely. Mr Williams mentioned that a temporary retractable bridge was provided at Lowestoft and we too looked into this possibility for Manchester Road. However, the cost would have added something like $10 \%$ to the contract and as an alternative route for pedestrians was available across the lock gates, this additional expense could not be justified.

150. Mr Pope also referred to the fact that, although the new bridge was sited on the south side of the lock to reduce the risk of damage by shipping, the two impacts which the old bridge suffered were in fact on that side. The ships concerned in these two events had previously been moored against the lead-in jetty on the south side and this had more to do with the position of the points of impact than the winds and tide prevailing at the time. In the minor accident to the new bridge which took place recently a ship struck the bridge slightly to the north of the centre line.

151. It was not thought that tapering the towers towards the base would have improved the appearance.

152. Several speakers showed interest in the design of the operating mechanism and I am obliged to Mr Craig and Mr Bird for providing some further details. When I prepared my Paper I was concerned to keep it down to a reasonable length and inevitably there were some features which had to be condensed. I hope, perhaps, to be able to amplify these aspects at a later date.

153. Mr Lewis made several interesting observations on the mechanism and I am glad that he endorses the application of high torque hydraulic motors. He asked for details of the characteristics of the motors and pumps and some of these are shown in Figs 33 and 34.

154. I also enthusiastically concur with Mr Lewis's condemnation of using inching motors and limit switches to land a moving bridge onto its bearings. The variable delivery pumps controlled by cams, which were developed for both the new PLA bridges, work very well in service and have proved both robust and reliable. It is necessary to provide for reducing speed at a pre-determined rate only at the limits of travel, to ensure that the bridge lands gently without shock. Although the inertia of a moving bridge is very large, there is generally only a problem of 'killing' the last 


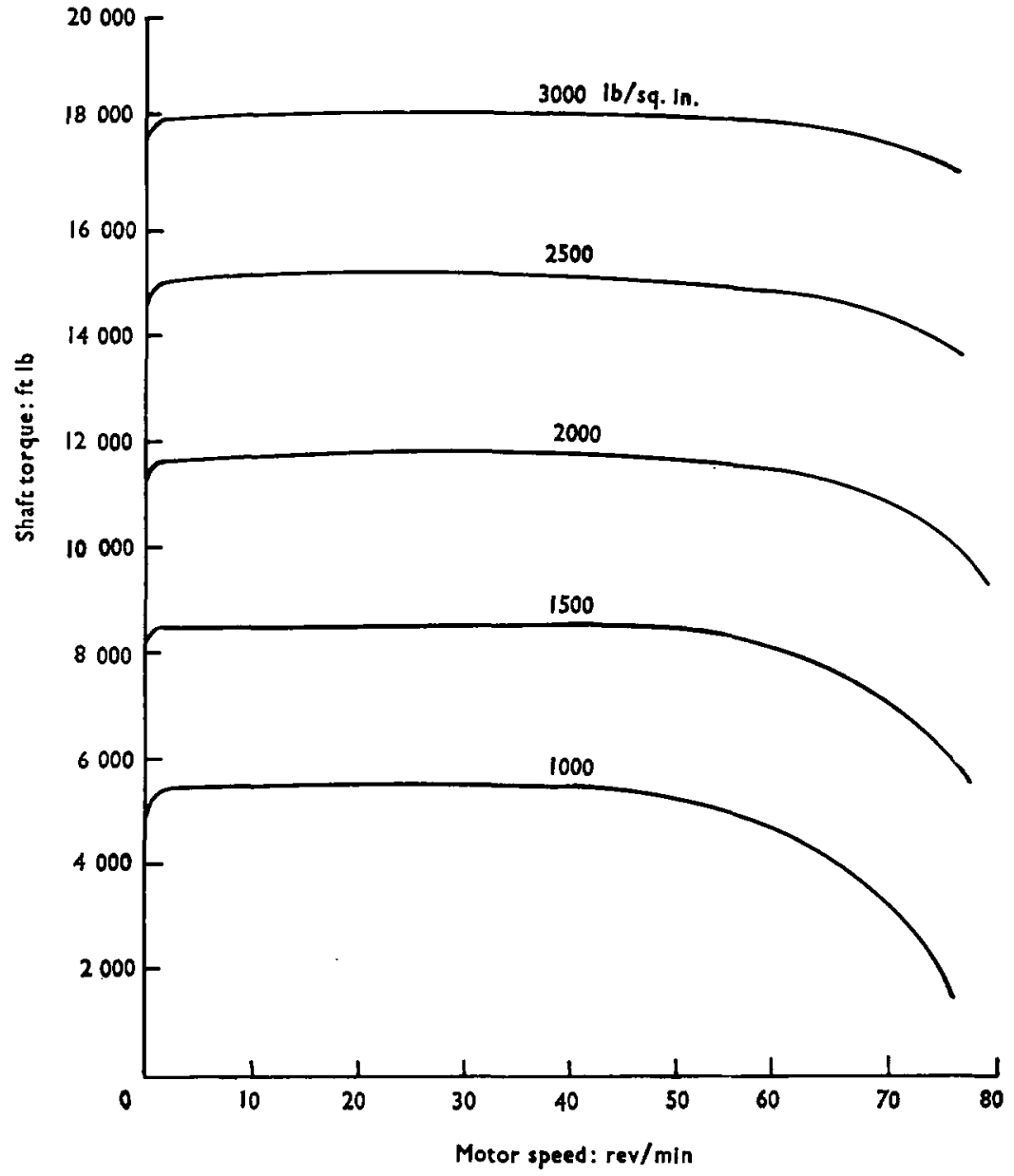

Fig. 33. Characteristics of MacTaggart, Scott Mark VI hydraulic motor

remaining bit just before the bridge stops and very sensitive control is required to achieve this. Acceleration from any position, and also stopping at an intermediate position, is not difficult with the hydraulic motor arrangement as momentary overloads are automatically relieved. To avoid a sudden application of the brakes when the bridge is stopped at an intermediate position a throttle valve was provided in the drain line to the tank. This slows down the fall of supercharge pressure within the brakes and ensures that they are not applied until after the bridge has been brought to rest by regenerative hydraulic pressure on the suction side of the motors. The brakes are thus generally intended to act only as clamps to hold the bridge safely in a stationary position.

155. Mr Rundle was also interested in the braking system. Each of the eight hydraulic motors has a multidisc brake unit mounted concentrically to operate on the 


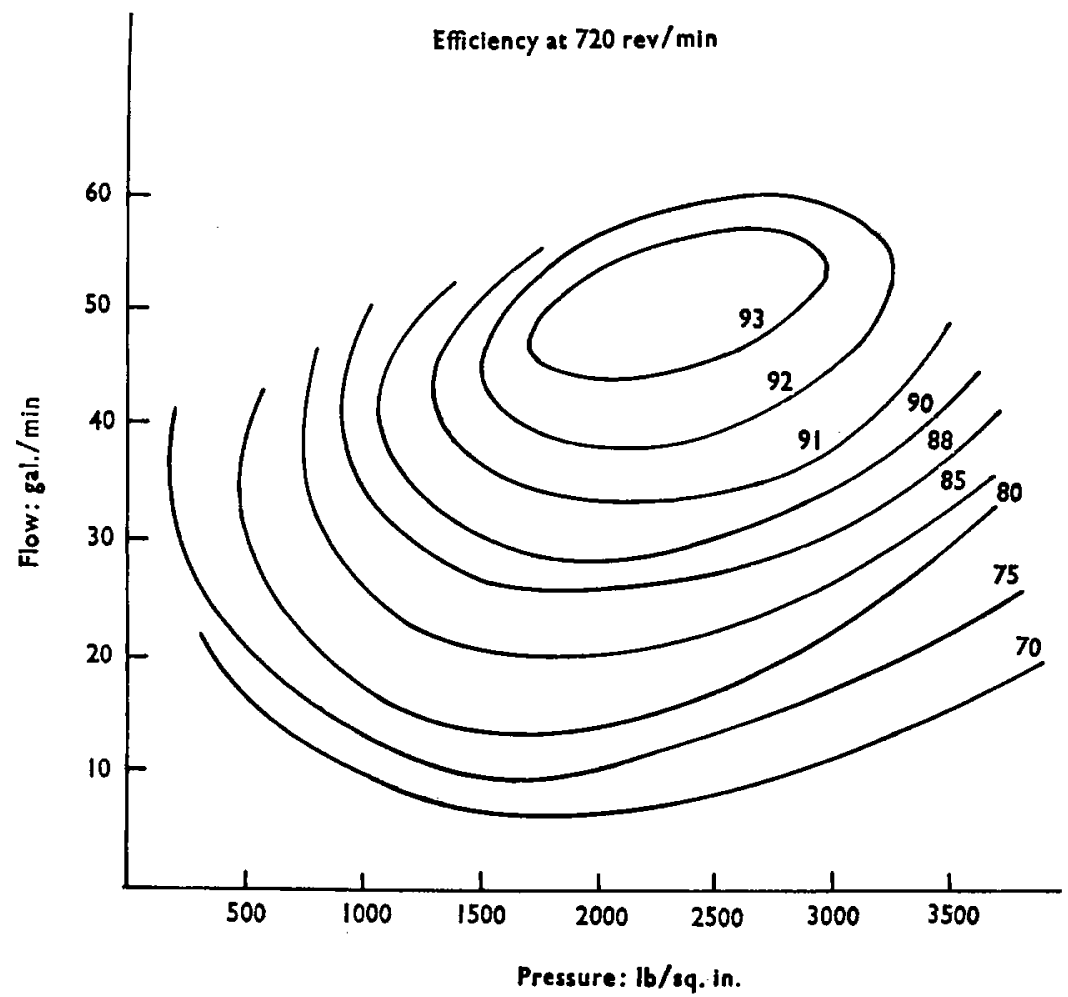

Fig. 34. Characteristics of MacTaggart, Scott Mark V variable delivery pump

common shafts driving the pinions. Spring loading applies the brakes and hydraulic pressure from the supercharge circuit releases them. The system is so arranged that release of the brakes is the last operation before the bridge moves and they are automatically applied in the event of a hydraulic or electric failure. These safeguards are in fact so effective that it was difficult to rotate individual motors during installation, and special provision had to be made for release of the brakes by means of separate hand pumps.

156. Mr Rundle also comments on the comparison which had been made between providing a new bridge or repairing the old and Mr Wilson outlined some of the reasons which lay behind his decision to renew. It was clear that not only would the repair require heavy expenditure, but in view of the condition of the old bridge, there would have been a real possibility that once started repairs would have proved more extensive than anticipated.

157. I very much agree that the presence of a little dirt in a hydraulic system can cause endless trouble and I was pleased that our contractor recognized the need for absolute cleanliness both during manufacture and installation. He also went to a lot of trouble to recirculate fluid and filter before the mechanism was run and in consequence absolutely no trouble from dirt has been experienced. As Mr Craig points out, once the system is clean, it is unlikely to be contaminated subsequently other than by carelessness during servicing. 
158. I am very much obliged to Mr Gabony for drawing attention to what the bridge means to the people living on the Isle of Dogs. At best, the lifting bridge is to them an inconvenience and, when the new bridge was designed, we tried to reduce this as far as we could. We can take some consolation in the thought that one modern bridge must be less of a trial than the five which used to lie on the main road.

159. Mr Huggins rightly draws attention to the reliance which was placed on finding good quality concrete in the quay wall beneath the old bridge. The fact that the towers could be secured by directly anchoring into the existing concrete was of great importance and helped materially towards making the design economic as a whole.

160. The importance of inspection has been mentioned by Mr Malcolm. In addition to the inspection described in $\$ 56$ the fundamental lining and levelling of principal structural components and the accurate manufacture and operation of mechanical parts, were also subject to inspection. It would have been difficult for the staff of the port authority to inspect the large number of different components involved properly and a specialist firm was consequently retained to act on their behalf.

161. Mr Beresford Hartwell laid emphasis on the dilemma which often faces those using an oil hydraulic system, of whether to adopt linear actuating cylinders or racks and motors. Cylinders have the important advantage of being much simpler and they could have been fitted quite well into the drawbridge layout. Their possible adoption was considered very carefully but it was decided that the rack and motor arrangement was preferred for two primary reasons. During operation of the bridge very precise and rigid control of the travel is required, particularly as the bearings are approached, and it was thought this would be difficult to achieve using hydraulic cylinders. In addition, it was necessary to have a braking system which was entirely separate from the hydraulics and this also would have been difficult to arrange, with sliding rather than rotary operation. We had no pre-conceived ideas about the best type of machinery to adopt but found that the optimum arrangement evolved quite naturally once the type of bridge had been selected and the layout of the main components settled. Other inherent benefits of hydraulics then followed as an additional bonus and I think that Mr Powell's remarks on starting torque, highlight an important one of these.

162. With roller bearings providing pivots there is little 'sticktion' inherent in the structure and the principal internal resistance to starting is that generated by the inertia of the moving parts. With direct mechanical drive this would normally have to be overcome by electric motors starting from rest and, as $\mathrm{Mr}$ Powell pointed out, this may induce heavy transient power demand. The electric prime movers of the hydraulic drive however start offload and it is not until they are turning at full speed, that force is applied to the bridge to commence movement. This force can rise up to, but not exceed, the maximum for which the system is designed and peak loading is avoided.

163. Mr Powell also referred to the necessity for maintaining the machinery while the bridge is in service. If a motor has to be put out of service it can be readily isolated from the hydraulic circuit and allowed to freewheel. It can subsequently be removed for maintenance quite simply, a lifting beam is provided for this purpose, and the bridge can continue in service without interruption. The brakes can also be dismounted without affecting operation and, indeed, any of the motor/brake units can be entirely removed leaving only the pinion shaft, bearings and housings. I would have thought that a hydraulic motor filled with oil would have been unlikely to actually seize in service and that a clutch in the drive was unnecessary.

164. Mr Powell pointed out some of the advantages to be gained from modern electric drive for bridges and I would agree that nowadays it is possible to obtain much more sophisticated control than hitherto. I would, however, suggest that most electric drives still require a transmission and that it is for this that the high torque/slow speed characteristics of hydraulics are so useful. 
165. I agree with Mr Sefton that, if dominant structures are to be seen, then it is worth attempting to make them look right. The arrangement of a fixed quadrant rack with driving pinions mounted on the end of the bridge span is, in my view, most suitable for bridges of trunnion bascule type. Particularly good examples are to be found in the Netherlands where the arrangement has been adopted for a number of bridges on major trunk roads.

166. While I also agreed with Mr Sefton's suggestion that lack of information does often stimulate a fresh approach it inevitably means that there is some repetition of ground work that could otherwise have been avoided. Several speakers have commented on my suggestion of standardization of loadings and other design criteria for moving bridges and attention has been drawn to some of the difficulties. However, Codes of Practice already cover a wide field of requirements for other structures and I suggest that something similar for moving bridges would be equally useful. Such a code is already published in Holland and provides useful guidance without inhibiting the basic judgement of the engineer.

\section{References}

1. Sefton W. Movable bridges with special reference to the Cherry Street bascule bridge in Toronto. Thesis, University of Toronto, September 1970.

2. Waddell J. A. L. Bridge engineering. John Wiley, New York, 1916.

3. HoveY O. E. Movable bridges. John Wiley, New York, 1927.

4. HoOL AND KINNE. Movable and long span steel bridges. McGraw-Hill, New York, 1943. 